\title{
Musik Liturgi Inkulturatif di Gereja Ganjuran Yogyakarta
}

\author{
Yohanes Don Bosko Bakok ${ }^{1}$ \\ Program Studi Seni Drama dan Musik, Fakultas Pendidikan Bahasa dan Seni, \\ Universitas Katolik Widya Mandira Kupang.
}

\begin{abstract}
ABSTRAK
Gereja Ganjuran merupakan salah satu Gereja Katolik di Yogyakarta yang sering menggunakan musik inkulturatif dalam perayaan liturgi. Penggunaan musik inkulturatif sering kali aspek budaya lebih mendominasi dibanding aspek liturgi yang dirayakan. Jenis musik dan instrumen tertentu yang tidak disetujui oleh sebagian besar umat untuk digunakan dalam perayaan liturgi pun tetap digunakan. Penelitian ini bermaksud mengkaji fenomenafenomena tersebut dalam perayaan Jumat Agung pada tanggal 22 April 2011 dengan berpedoman pada ketentuanketentuan mengenai musik liturgi yang berlaku dalam Gereja Katolik universal. Mengkaji fenomena ini digunakan teori inkulturasi dengan metode kualitatif. Hasil penelitian menunjukkan bahwa musik liturgi inkulturatif yang digunakan dalam perayaan ada yang sesuai dan ada yang tidak sesuai dengan ketentuan-ketentuan pada musik liturgi.
\end{abstract}

Kata kunci: musik liturgi, inkulturatif, Ganjuran.

\section{ABSTRACT}

The Inculturated Liturgical Music at the Sacred Heart of Jesus Church of Ganjuran Yogyakarta. The Sacred Heart of Jesus Church of Ganjuran is one of the Catholic Churches in Yogyakarta that often uses in culturated music in the liturgical celebration. In using the inculturated music, the cultural aspects often be more dominant than the celebrated liturgy. Certain types of music instruments that are not approved by the majority of people to be used in the celebration of the liturgy are still in use. This study is intended to analize this phenomenon, especially in the celebration of Good Friday on April 22nd 2011 based on the provisions of the liturgical music that are applicable in the universal Catholic Church. The theory that is used to study the problem of this research is the theory of inculturation, and the research method is qualitative method. The result of the research showed that some inculturated liturgical music used in the celebration of Good Friday on April 22nd 2011 was appropriate, and some of it was not appropriate based on the provisions of liturgical music.

Keywords: liturgy music, inculturated, Good Friday, Ganjuran.

\section{Pendahuluan}

Musik liturgi baik musik vokal maupun musik instrumen adalah musik yang digunakan dalam perayaan liturgi umat Katolik. Musik liturgi memainkan peranan penting untuk menghantar umat ke dalam suasana hikmat ketika menjalankan kebaktian kepada Tuhan sehingga menjadi bagian integral dari liturgi Gereja Katolik (Hardawiryana, 1990: 44). Nyanyian liturgi bukan saja mengiringi perayaan liturgi melainkan juga menjadi bagian dari liturgi itu sendiri karena lirik tertentu dari nyanyian tersebut merupakan doa-doa liturgis.

Musik liturgi yang dipakai dalam ibadat atau perayaan Ekaristi biasanya disesuaikan dengan tema liturgi. Lirik lagunya pun mencerminkan firman Tuhan yang tertera dalam Kitab Suci. Secara umum tema-tema liturgi tersebut dibagi menjadi tiga masa utama sesuai penanggalan liturgi yaitu; masa biasa, masa Natal dan masa Paskah. Masa biasa adalah masa di antara masa Natal dan Paskah, di antara masa Paskah dan masa Natal berikutnya. Termasuk dalam masa Natal adalah masa Adventus yaitu masa persiapan bagi segenap umat Katolik untuk menyambut perayaan Natal. Termasuk masa Paskah adalah masa pra Paskah yaitu masa persiapan untuk menyambut perayaan Paskah (Komisi Liturgi KWI, 1993: XVIII-XX). Perayaan Jumat Agung yang menjadi fokus tulisan ini merupakan perayaan yang diselenggarakan dalam masa pra Paskah dan secara khusus merenungkan penderitaan dan wafat Tuhan Yesus demi mendatangkan keselamatan bagi umat manusia.

Tema umum di atas menggunakan musik liturgi yang disesuaikan dengan tema-tema khusus perayaan Ekaristi atau ibadat seperti perayaan

1 Alamat korespondensi: Prodi Sendratasik, Universitas Katolik Widya Mandira Kupang. Jalan A. Yani No. 50-52 Merdeka, Kupang - NTT. Email: jokobako@yahoo.com. HP: 085239066254. 
nikah, perayaan kematian atau misa/ibadat arwah, perayaan ulang tahun, perayaan syukur wisuda dan lain sebagainya. Demi memenuhi kebutuhan akan nyanyian pada tiap perayaan sesuai tematema tersebut, Pusat Musik Liturgi (PML) sudah menerbitkan buku-buku nyanyian resmi yang dapat digunakan oleh umat antara lain, Madah Bakti, Kidung Adi, Mazmur Tanggapan, Pujian Senja dan Pujian Malam serta beberapa buku nyanyian lainnya.

Perayaan liturgi merupakan perayaan umat yang tidak bisa dipisahkan dari konteks sosial budaya mereka sehingga sejak Konsili Vatikan II tahun 1962-1965, gereja membuka peluang bagi masuknya unsur-unsur budaya tradisional dalam liturgi. Salah satu unsur budaya tradisional yang lazim digunakan dalam liturgi adalah kesenian seperti seni musik, seni tari, seni sastra dan seni rupa. Secara spesifik, musik tradisional yang biasa digunakan dalam liturgi disebut sebagai musik liturgi inkulturatif. Disebut musik inkulturatif karena didalamnya terdapat pertemuan antara aspek liturgi universal dan aspek tradisi yang bertujuan menghantar umat dari latar belakang kehidupan dan budaya mereka yang kongkret kepada perjumpaan dengan Allah dalam doa dan pujian. Pertemuan tersebut terjadi proses interaksi sedemikian rupa sehingga baik aspek liturgi maupun tradisi mengalami transformasi (Prier, 1999:7). Keselarasan antara nilai-nilai liturgis dan nilai-nilai tradisi sangat ditekankan sehingga tidak terjadi pertentangan di antara keduanya.

Gereja Ganjuran adalah salah satu Gereja Katolik di Yogyakarta yang sering menggunakan musik inkulturatif dalam liturgi. Hampir setiap Minggu ada perayaan liturgi inkulturatif di gereja ini di mana musik inkulturatif juga digunakan. Demi memfokuskan pembahasan, dalam tulisan ini penulis hanya membatasi pada hasil peneitian mengenai musik liturgi inkulturatif dalam Perayaan Jumat Agung yakni perayaan untuk memperingati penderitaan dan wafat Tuhan Yesus Kristus tanggal 22 April 2011. Masalah yang dianalisis di sini adalah apakah musik liturgi inkulturasi yang digunakan dalam perayaan Jumat Agung tersebut sudah sesuai dengan ketentuan-ketentuan tentang musik liturgi?

Membedah masalah ini penulis menggunakan teori inkulturasi yaitu teori yang menjelaskan tentang suatu proses latihan yang dengannya seorang individu diintegrasikan ke dalam kebudayaan pada zaman dan tempat tertentu (Bakker, 1984: 103). Proses yang sama terjadi juga dalam musik liturgi inkulturatif dimulai dengan pertemuan antara musik liturgi gereja tradisional dengan kebudayaan tertentu. Dalam pertemuan tersebut terjadi proses penyesuaian dari musik liturgi gereja tradisional dengan kebudayaan setempat tanpa menghilangkan atau mengaburkan nilai-nilai religius yang terdapat dalam musik liturgi gereja tradisional tersebut. Perubahan terlihat antara lain pada bahasa yang digunakan dalam lagu liturgi, alat musik dan motif-motif lagu, sedangkan yang masih tetap dipertahankan antara lain isi dan makna lagu sesuai peranannya dalam perayaan liturgi. Nampak jelas di sini bahwa ada aspek tertentu dari musik liturgi Gereja tradisional yang telah mengalami perubahan dan ada aspek lain yang masih dipertahankan.

Metode penelitian yang penulis gunakan dalam penelitian ini adalah metode kualitatif, sedangkan pendekatan yang digunakan adalah pendekatan studi kasus. Metode kualitatif dirasa cocok dalam penelitian ini karena penulis ingin memahami secara baik masalah yang ada melalui pengamatan langsung dan wawancara yang mendalam. Penelitian studi kasus dipilih karena penulis sendiri sudah memiliki gambaran umum mengenai musik liturgi dan ingin mengkaji tentang kasus spesifik yang terjadi di Gereja Ganjuran berkaitan dengan musik liturgi tersebut. Kasus tersebut diteliti secara komprehensif dengan mewawancarai pihak-pihak terkait antara lain pastor paroki Ganjuran, penanggungjawab seksi musik liturgi pada perayaan Jumat Agung tanggal 22 April 2011, pemain gamelan, pemain trebangan, wakil umat yang hadir pada perayaan tersebut serta informan yang memahami lirik lagu-lagu yang digunakan.

\section{Sejarah dan Landasan Konstitusional Musik Liturgi}

Musik liturgi Gereja Katolik adalah musik yang digunakan dalam liturgi atau kebaktian umat Katolik, baik musik vokal maupun musik instrumen. Pemakaiannya pada kalangan umat Katolik sendiri, istilah musik atau nyanyian liturgi terkadang dipertukarkan secara kurang tepat dengan istilah musik atau nyanyian rohani. Musik atau nyanyian liturgi adalah musik atau nyanyian 
yang pantas dan diijinkan dalam kegiatan-kegiatan liturgis yaitu perayaan Ekaristi dan kegiatankegiatan ibadat, sedangkan musik atau nyanyian rohani digunakan untuk keperluan-keperluan keagamaan lainnya diluar perayaan liturgi. Bila mengacu pada aturan liturgi yang diwariskan dalam tradisi Gereja, lagu-lagu rohani sebenarnya tidak diijinkan untuk dipakai dalam perayaan Ekaristi karena tidak semua lagu-lagu tersebut sakral, ditulis dengan tujuan untuk dipakai dalam perayaan liturgi dan memiliki lirik sesuai tema perayaan.

Musik liturgi yang kita kenal pada saat ini telah melewati proses perkembangan yang panjang. Dalam proses perkembangan itu, musik liturgi senantiasa mengalami perubahan dan pembaharuan selaras perkembangan dan perubahan zaman dari waktu ke waktu. Selain itu, musik liturgi juga mengalami perkembangan dan perubahan akibat proses penyesuaian dengan aneka budaya dan kebiasaan di banyak bangsa dan negara. Karena itulah musik liturgi yang dibawa oleh para misionaris ke bangsa-bangsa dan negara tersebut tidak semuanya dapat diterima secara utuh karena ada yang tidak sesuai dengan budaya dan kebiasaan setempat.

Musik liturgi Katholik dimulai bersamaan dengan muncul dan berkembangnya kekristenan. Pada masa hidup Yesus di Nasareth, umat sudah terbiasa membawakan doa dalam bentuk nyanyian. Yesus sendiri bersama para murid-Nya menyanyikan mazmur hallel pada perjamuan malam terakhir (Mt. 26:30). Mazmur hallel yang dimaksud diambil dari kitab Mazmur BAB 113-118 dan 134-136. Tata urutan ibadat yang dijalankan umat pada masa itu masih mengikuti ritus Yahudi yang diwariskan dari generasi-generasi sebelumnya (Fellerer, 1961: 9).

Landasan konstitusional utama musik liturgi Gereja Katolik adalah Dokumen Konsili Vatikan II, terutama pada bagian Konstitusi Tentang Liturgi Suci no. 112-121. Isi dokumen ini antara lain membahas tentang martabat musik liturgi, liturgi yang meriah, pelestarian khasanah musik liturgi, pendidikan musik, nyanyian gregorian dan polifoni, penerbitan buku-buku nyanyian gregorian, nyanyian rohani umat, musik liturgi di daerah-daerah misi, orgel dan alat-alat musik lainnya, panggilan para pengarang musik.
Berdasarkan landasan konstitusional musik liturgi Gereja Katolik di atas dan dokumendokumen lain tentang musik liturgi, dirumuskan ketentuan-ketentuan tentang musik liturgi sebagai berikut: (1) Musik liturgi harus sesuai dengan tema liturgi yang dirayakan (Hardawiryana, 1990: 44). Khusus untuk perayaan ekaristi, lagu-lagu proprium disesuaikan dengan tema perayaan sedangkan lagu-lagu ordinarium mengikuti teks liturgi yang resmi (Prier, 2010: 8); Proprium yaitu lagu-lagu yang dinyanyikan khusus untuk hari-hari tertentu dan rumusannya bisa berubah-ubah sesuai tema perayaan. Termasuk dalam lagu ordinarium adalah lagu pembuka, antar bacaan, bait pengantar Injil, persiapan persembahan, komunio dan penutup. Ordinarium yaitu lagu-lagu yang rumusannya tetap dalam setiap perayaan ekaristi. Yang termasuk lagu ordinarium adalah lagu Tuhan Kasihanilah (Kyrie), Kemuliaan (Gloria), Aku Percaya (Credo), Kudus (Sanctus) dan Anak Domba Allah (Agnus Dei) (2) Melibatkan partisipasi aktif umat dalam bernyanyi (Hardawiryana, 1990: 44-46); (3) Memupuk kesatuan hati umat untuk menghayati misteri keselamatan yang dirayakan (Hardawiryana, 1990: 44 dan 46); (4) Lagu-lagu yang digunakan dalam perayaan liturgi disesuaikan dengan tradisi dan kemampuan umat setempat (Hardawiryana, 1990: 45-46).

\section{Musik Liturgi Inkulturatif}

Pemahaman tentang musik liturgi inkulturatif pertama-tama perlu diketahui pengertian inkulturasi itu sendiri. Kata inkulturasi terdiri dari awalan in yaitu suatu proses ke dalam dan akar kata cultura yang berarti pengolahan atau budaya. Inkulturasi merupakan suatu proses pengungkapan suatu nilai dalam wujud kebudayaan tertentu (Prier, 2009: 71).

Berdasarkan pengertian inkulturasi tersebut maka musik liturgi inkulturatif merupakan musik liturgi yang disesuaikan dengan latar belakang kebudayaan tertentu. Proses penyesuaian itu bisa dalam kaitan dengan musik vokal, instrumen maupun kedua-duanya. Untuk musik vokal, yang disesuaikan dengan kebudayaan setempat bisa liriknya saja, melodinya saja atau kedua-duanya.

Proses inkulturasi dalam musik liturgi sudah terjadi sejak ajaran kekristenan mulai diwartakan kepada bangsa-bangsa lain selain bangsa Yahudi. 
Ketikamenerimaajaran Kristusdan percayakepadaNya, bangsa-bangsa tersebut mulai membawakan doa-doa dan nyanyian liturgi yang diajarkan oleh para pewarta Injil namun dalam gaya baru sesuai dengan kebudayaan mereka sendiri. Akibatnya, nyanyian-nyanyian itu menjadi sangat bervariasi dari satu daerah ke daerah yang lain, dari suatu bangsa ke bangsa yang lain (Fellerer, 1961: 9).

Pada abad $4 \mathrm{M}$ musik liturgi di Eropa Timur disesuaikan dengan bentuk musik setempat. Penyesuaian itu diprakarsai oleh uskup Ambrosius di Milano dengan tujuan agar umat tidak merasa asing dengan nyanyian liturgi yang mereka bawakan dalam ibadat. Hal yang sama terjadi juga pada abad 10-11 di Eropa Utara terutama berkaitan dengan lagu Gregorian dalam ibadat sesuai dengan kebiasaan mereka. Lagu tersebut tidak lagi dibawakan dalam satu suara (monofonik) tetapi dalam lebih dari satu suara (polifonik) yang dikenal dengan sebutan organum (Prier, 1999: 9). Penyusunan organum atau lagu polifon pada lagu Gregorian itu dibuat dengan cara menambahkan suara lain yang bergerak paralel dengan melodi utama dalam interval quint atau quart di atas atau di bawahnya sehingga terjadilah parallel quint, quart dan oktaf (Machlis, 1977: 220).

Proses inkulturasi musik liturgi terus berlangsung pada abad-abad selanjutnya di berbagai bangsa kecuali di sekitar abad 16 saat Gereja Katholik melakukan konsolidasi internal berkenaan dengan gerakan reformasi. Pada abad 19 gereja mulai terbuka lagi untuk berdialog dengan budaya lokal termasuk dalam kaitannya dengan musik liturgi. Perubahan dalam proses dialog tersebut terjadi pada abad 20, tepatnya pada tahun 19621965 ketika Konsili Vatican II memulai suatu era baru kehidupan menggereja dalam kaitan dengan budaya-budaya lokal. Musik tradisional dan alatalat musik selain orgel pipa mulai diijinkan untuk digunakan dalam ibadat. Inilah langkah maju dalam proses inkulturasi yang terus berkembang sampai saat ini (Prier, 1999: 10-11).

Di Indonesia perkembangan musik liturgi inkulturatif dimulai setelah Perang Dunia II (1934-1945) ketika Mgr. Van Bekkum, SVD menyusun buku Dere Serani bersama para pemusik di Manggarai-Flores. Buku tersebut berisikan nyanyian-nyanyian liturgi yang ditulis dalam bahasa daerah Manggarai. Tahun 1957 P. Vincent Lechovic, SVD menulis buku Tsi Taneb uis Neno yang berisikan nyanyian liturgi dalam bahasa Dawan-Timor. Tahun 1961 di Jawa diterbitkan buklet berjudul Kidungan Sutji Lagu Djawi yang berisikan lagu-lagu untuk kebutuhan ibadat selain misa yang sudah dipersiapkan sejak 1956 atas prakarsa Mgr. A. Soegijapranata, SJ (Prier, 2007: 7).

Musik liturgi inkulturatif di Indonesia mengalami perkembangan luas pada tahun-tahun selanjutnya, baik musik karawitan di Jawa maupun musik-musik lainnya di luar Jawa. Hal ini didukung oleh inisiatif dan kerja keras Pusat Musik Liturgi (PML) Yogyakarta yang berdiri pada tahun 1971. Selama lebih dari 30 tahun, seperti yang dijelaskan oleh Paul Widyawan (2007: 134), PML Yogyakarta sudah menyelenggarakan sedikitnya 50 lokakarya musik Liturgi di berbagai daerah di Indonesia untuk mensosialisasikan dan mengembangkan musik liturgi inkulturatif. Sampai saat ini lagu-lagu inkulturasi tersebut masih digunakan dalam perayaan-peryaan ekaristi maupun ibadat-ibadat lainnya di berbagai paroki di tanah air.

\section{Musik Liturgi Inkulturatif Di Gereja Ganjuran}

Gereja Ganjuran adalah salah satu gereja paroki di keuskupan agung Semarang yang secara administratif berada dalam wilayah kabupaten Bantul propinsi Daerah Istimewa Yogyakarta. Paroki yang terletak kurang lebih $17 \mathrm{~km}$ ke arah Selatan dari kota Yogyakarta ini memiliki 7 stasi yaitu Tambran, Kretek, Baros, Kurabaya, Gunturgeni, Gilangharjo dan Ngireng-Ireng (Hadi, 2006: 90). Pada umumnya umat dari paroki ini bekerja sebagai petani di sawah maupun ladang dan hanya sebagian kecil yang bekerja sebagai pegawai negeri maupun swasta serta guru di sekolah (Hadi, 2006: 115-116). Gereja ini didirikan pada tanggal 16 April 1924 yang ditandai dengan peletakan batu pertama oleh keluarga Schmutzer (Susantina: 2001: 56).

Perkembangan inkulturasi di gereja Ganjuran telah melewati proses yang panjang dan didukung oleh kerja keras para fasilitator dan motivator yang mensosialisasikannya kepada umat. Fasilitator dan motivator tersebut adalah anggota dewan paroki dan para katekis di gereja Ganjuran. Secara konkret inkulturasi musik liturgi di gereja ditandai dengan pemakaian musik gamelan Jawa sebagai pengiring 
lagu-lagu liturgi terutama dalam perayaan Natal dan Paskah (Susantina: 2001: 64). Musik gamelan memiliki hubungan erat dengan kehidupan orang Jawa yang ditandai semangat musyawarah dan gotong royong. Ketika mementaskan musik gamelan, masing-masing penabuh memainkan instrumen namun dikendalikan oleh irama kendang dan ditutup dengan pukulan gong (Prier, 1999: 21).

Musik gamelan dan nyanyian liturgi bahasa Jawa nampak menjadi kesenian yang indah karena dalam dirinya sendiri terdapat nilai-nilai luhur yang selaras dengan iman dan ketaqwaan umat yang merayakannya, disinilah letak hubungan antara seni dan agama. Kesenian diterima untuk digunakan sebagai sarana pemujaan kepada Allah karena di dalam dirinya terdapat isi, makna dan nilai-nilai moral yang mendukung penghayatan kepercayaan yang dianut (Hadi, 2006: 265). Liturgi bila diiringi musik gamelan dan gendhing yang sesuai akan mendukung umat dalam menghayati nilai-nilai liturgi yang dirayakan.

Selain musik gamelan, instrumen lain yang juga digunakan untuk mengiringi perayaan liturgi di gereja Ganjuran adalah musik trebangan dan gejok lesung. Musik trebangan didominasi oleh instrumen rebana yang terdiri dari satu trebang besar (gong), satu trebang sedang (kempul), dua trebang kecil (tung dan tang), satu kendang dan dua angklung (Pasrah, wawancara, 26 Mei 2011). Gejok lesung merupakan alat musik yang berasal dari alat penumbuk padi tradisional yang terdiri dari sebuah kayu berdiameter $75 \mathrm{~cm}$, panjangnya 2 meter yang sebagiannya dilubangi dan alat penumbuk yang disebut alu. Para pemainnya terdiri dari 3 atau 5 orang, biasanya wanita atau ibu-ibu (Hadi, 2006: 132).

Sampai saat ini proses inkulturasi musik liturgi masih tetap dipertahankan di gereja Ganjuran. Secara rutin musik inkulturasi digunakan dalam perayaan ekaristi pada malam Jumat pertama dan malam 10 Novembersedangkan perayaan-perayaan besar lainnya disesuaikan dengan permintaan dan kebutuhan umat. Penggunaan musik liturgi inkulturatif di gereja Ganjuran didukung dan selalu berada di bawah pengawasan pastor paroki setempat. Gereja Ganjuran merupakan bagian dari Keuskupan Agung Semarang dan Gereja Katolik universal yang patuh pada ketentuan-ketentuan mengenai musik liturgi.

\section{Analisis Lagu-lagu dan Instrumen dalam Perayaan Jumat Agung.}

Lagu-lagu yang dinyanyikan pada perayaan Jumat Agung tanggal 22 April 2011 antara lain, Sungkawa (susah), Ayak Ayak Tlutur (sedih), Gya Sumewa (semua menghadap), Gusti Midhangetna (Tuhan Dengarkanlah), Ngabekti Salib, Salib Suci, Megatruh, Ing Ratri Njeng Gusti, Atur Roncen, Sri Yesus Di, Rama Kawula, Linuhurna Gusti, Puji Luhung dan Sri Yesus Manis Ing Manah.

Lagu Sungkawa dinyanyikan oleh seorang solis pria diiringi slenthem dengan volume yang halus. Alunan melodinya mengekspresikan kedukaan mendalam sesuai pengertian judulnya, susah. Dari liriknya kita mengetahui bahwa lagu ini juga mengandung makna pertobatan dan permohonan rahmat pengampunan dari Tuhan atas segala dosa. Dasar pemikirannya yakni, Tuhan menderita dan wafat akibat dosa manusia. Lagu Sungkawa dalam urutan perayaan Jumat Agung berperan mengiringi arak-arakan imam dan para petugas liturgi menuju altar sekaligus mempersiapkan umat untuk memulai perayaan. Sampai di depan altar imam langsung berlutut sebagai ungkapan kesedihan mengenang penderitaan dan wafat Tuhan sementara itu solis tetap menyanyikan Sungkawa.

Ungkapankesedihan dan penyesalan mendalam atas dosa dilanjutkan dengan menyanyikan lagu Ayak Ayak Tlutur. Ayak-ayak merupakan sebutan untuk bentuk gendhing yang jumlah kenong, kempul serta gong tidak menentu sedangkan tlutur berarti lagu, tembang atau gendhing yang mengungkapkan kesedihan. Peranan lagu Ayak Ayak Tlutur masih sama dengan lagu sebelumnya yaitu mengiringi arak-arakan imam dan para petugas liturgi menuju altar sekaligus mempersiapkan umat untuk memulai perayaan. Liriknya menggambarkan penderitaan Yesus untuk menebus dosa manusia dan ungkapan penyesalan dan permohonan ampun atas dosa yang telah dilakukan. Umat manusia sudah sepantasnya dihukum akibat dosa yang telah dilakukan namun berkat penebusan Kristus dibebaskan dan memperoleh jaminan untuk memasuki kehidupan yang kekal. Rahmat penebusan Kristus itu didukung pula oleh penyesalan dan pertobatan umat yang ditebus.

Gya Sumewa adalah lagu pertama dalam perayaan ini yang diiringi terbangan. Iramanya 
berbeda dengan gamelan untuk lagu-lagu lain karena agak hidup dan memiliki ritme yang tegas. Lagu ini dipilih sebagai lagu antar bacaan I, di antara bacaan I dan bacaan II. Dari segi tempo dan ritmenya memang kurang mencerminkan suasana duka yang mewarnai perayaan Jumat Agung. Walaupun demikian, liriknya mengungkapkan penderitaan Tuhan Yesus dan kesediaan-Nya untuk memikul salib demi menebus dosa manusia. Selain itu terdapat ajakan bagi umat untuk menyembah Tuhan Yesus karena jasa penebusanNya. Penyembahan ini juga disertai ungkapan syukur karena Tuhan berkenan membatalkan hukuman-Nya atas manusia berdosa. Tuhan menghendaki agar manusia tetap bersatu dengan Dia tidak hanya di dunia ini melainkan sampai pada kehidupan yang kekal.

Makna lagu Gusti Midhangetna tidak jauh berbeda dengan lagu-lagu sebelumnya yaitu memohon pengampunan dari Tuhan atas dosa. Lagu ini merupakan lagu antar bacaan II yang dinyanyikan di antara bacaan II dan Injil. Peranannya adalah menghantar umat dalam merenungkan bacaan II dan mempersiapkan hati untuk mendengarkan bacaan Injil. Liriknya sesuai dengan isi bacaan II yaitu memohon rahmat keselamatan dari Tuhan karena hanya pada Tuhanlah terdapat keselamatan yang kekal. Makna lagu ini sesuai pula dengan isi bacaan Injil yaitu kisah sengsara Yesus demi menebus dosa umat manusia.

Lagu Ngabekti Salib mengandung ajakan untuk menghormati salib suci. Pertama-tama imam mengajak umat untuk melihat salib tempat bergantung Yesus dalam bentuk nyanyian dan ditanggapi umat dengan nyanyian pula. Nyanyian yang sama dibawakan tiga kali berturut-turut pada tingkatan pitch yang berbeda, naik setengah laras pada setiap pengulangan. Maksud pengulangan tersebut yakni agar umat semakin memfokuskan perhatian pada salib Kristus dan merenungkan pengorbanan-Nya demi keselamatan manusia. Salib dengan demikian tidak lagi merupakan lambang penghinaan melainkan lambang kemenangan bagi semua orang yang percaya pada Kristus. Dalam masyarakat Yahudi, penyaliban adalah hukuman mati yang diberikan kepada para penjahat karenaitu ketika Yesus disalibkan, terdapat dua orang penjahat yang disalibkan bersama Dia di bagian kiri dan kanan-Nya. Yesus disalibkan sebagai penjahat walaupun Ia tidak melakukan kesalahan, karena itu penderitaan dan wafat-Nya di salib menjadi tebusan bagi orang-orang berdosa. Tanggapan umat di sini disertai ajakan terhadap umat yang lain untuk menghormati salib Kristus. Dalam urutan perayaan liturgi Jumat Agung, lagu ini mengawali upacara penghormatan salib.

Lagu salib suci mengiringi prosesi umat untuk memberi penghormatan pada salib. Lirik bagian solo melukiskan pengorbanan Kristus sendiri. Ia rela wafat di salib dan jasad-Nya dikuburkan namun tiga hari kumudian bangkit lagi dalam kemuliaan. Pengorbanan Kristus ini merupakan bukti cinta-Nya tanpa pamrih kepada manusia. Cinta itu tiada berakhir bagaikan air yang senantiasa mengalir. Hal ini dilukiskan dengan indah dalam lirik lagu bagian refrain. Lagu yang diiringi musik trebangan ini masih termasuk dalam upacara penghormatan salib.

Makna yang terkandung dalam lagu Megatruh masih berupa ajakan untuk memberi penghormatan pada salib suci sehingga sesuai dengan penempatannya dalam upacara penghormatan salib. Di dalamnya terdapat pula pengharapan akan rahmat belas kasih Tuhan. Irama dan alur melodi lagu yang juga diiringi musik trebangan ini memang agak hidup namun liriknya tetap mengungkapkan kesedihan dan penyesalan atas dosa.

Sebelum sampai pada momen penderitaan dan kematian-Nya, Tuhan Yesus sudah mengalami sakratul maut pada malam sebelumnya di taman Getsemani. Saat itu Ia berdoa kepada Bapa di surga dan penderitaan-Nya sudah dimulai di sana. Ia gelisah dan sangat takut sampai mengeluarkan peluh berupa titik-titik darah yang menetes ke tanah (Luk. 22:44). Walaupun demikian, Ia tidak menghindar dari hukuman mati karena itu Ia berdoa: "Ya Bapa, jikalau cawan ini tidak mungkin lalu, kecuali apabila Aku meminumnya, jadilah kehendak-Mu" (Mt. 26:42). Permulaan penderitaan Yesus di taman Getsemani itu dilukiskan dalam lagu Ing Ratri Njeng Gusti. Walaupun singkat, lagu ini mampu menghantar umat ke dalam permenungan tentang ketaatan Yesus pada kehendak Bapa dan keberanian-Nya untuk menghadapi kematian demi keselamatan manusia.

Lagu Atur Roncen menggambarkan tentang pemberian bunga mawar yang indah pada Tuhan 
sebagai ungkapan penghormatan dan cinta kepada-Nya. Lagu ini sesuai dengan ungkapan penghormatan salib dalam perayaan ini. Di banyak gereja lain, umat biasanya memberi penghormatan pada salib dengan mengecup salib namun pada kesempatan ini diungkapkan dengan menabur bunga mawar yang harum dan segar pada salib. Mawar itu menutupi seluruh bagian korpus Yesus pada salib yang dibaringkan di atas meja pendek di depan altar. Acara penaburan bunga ini sesuai dengan kebiasaan umat setempat yakni memberikan karangan bunga bagi anggota keluarga atau sahabat yang telah meninggal dunia. Lagu Atur Roncen yang dibawakan pada bagian ini berisikan juga alasan umat menaruh hormat pada Salib Kristus dan meletakan bunga mawar di atasnya yaitu karena Kristus telah rela memanggul salib dan wafat untuk menyelamatkan manusia.

Lagu Sri Yesus Di menggambarkan martabat Yesus sebagai raja yang menderita. Makna yang terkandung di dalamnya yaitu kerendahan hati Yesus karena ketaatan-Nya pada kehendak Bapa dan cinta-Nya pada manusia. Walaupun memiliki martabat raja, Ia rela merendahkan diri-Nya sampai wafat di kayu salib. Dalam urutan perayaan Jumat Agung ini Sri Yesus Di termasuk lagu pengiring upacara penghormatan salib. Dengan menyanyikan atau mendengar lagu ini umat dihantar untuk merenungkan misteri salib sebagai tanda kemenangan setiap orang Kristen dan turut mewarisi martabat rajawi Yesus Kristus.

Lagu Rama Kawula (Bapa Kami) mengungkapkan doa yang diajarkan oleh Yesus Kristus kepada pengikut-Nya. Dalam lagu yang singkat ini terkandung unsur-unsur penting sebuah doa yaitu pujian atau syukur dan permohonan. Lagu ini diawali dengan menghaturkan pujian atas kemuliaan Allah Bapa di surga diikuti beberapa rangkaian permohonan, di antaranya: memohon agar Allah mewujudkan Kerajaan-Nya di dunia dan agar kehendak-Nya terlaksana di dunia seperti di surga, memohon karunia rejeki dan rahmat pengampunan dosa, memohon agar tidak dimasukan ke dalam percobaan dan dibebeaskan dari segala yang jahat. Dalam liturgi Jumat Agung, lagu Bapa Kami mengawali upacara komuni.

Lagu Linuhurna Gusti termasuk lagu komuni, berisikan pujian pada Allah Tritunggal Maha Kudus, Bapa, Putra dan Roh Kudus serta Bunda Maria dan Santo Yosep. Berdasarkan liriknya, terutama pujian pada Allah Tritunggal Maha Kudus, lagu ini sama dengan lagu kemuliaan (Gloria), termasuk dalam kelompok lagu ordinarium untuk perayaan ekaristi. Seturut ketentuan liturgi, selama masa prapaskah yang berpuncak pada perayaan Jumat Agung, lagu kemuliaan tidak dinyanyikan dalam perayaan liturgi. Alasannya karena lagu ini bernuansa gembira dan merupakan ungkapan sukacita, sementara dalam masa prapaskah, apalagi Jumat Agung, umat terlibat dalam kesedihan mengenang penderitaan dan wafat Tuhan Yesus. Selain itu, dalam lagu kemuliaan biasanya yang dipuji dan dimuliakan hanya ketiga pribadi Allah Tritunggal yakni Allah Bapa, Allah Putra dan Allah Roh Kudus, tidak termasuk Bunda Maria dan Santo Yosep. Bunda Maria dan Santo Yosep adalah manusia biasa yang mendapat kasih karunia istimewa dari Allah dan tidak dimuliakan sejajar dengan Allah Tritunggal.

Lagu Puji Luhung menggambarkan suasana yang lain dan agak berseberangan dengan tema perayaan Jumat Agung. Liriknya berisikan penggalan nyanyian pujian Maria (magnificat) yang terdapat dalam Luk. 1:46-48. Lagu ini sengaja dinyanyikan untuk menampilkan tokoh Maria sebagai ibu Yesus yang turut terlibat dalam karya keselamatan yang diemban Yesus puteranya namun tidak tepat dibawakan pada perayaan Jumat Agung.

Lagu Sri Yesus Manis Ing Manah melukiskan tentang karya keselamatan yang diemban oleh Yesus Kristus. Keselamatan itu membawa sukacita sejati bagi setiap orang yang percaya kepada-Nya. Tidak ada sesuatu pun di dunia ini yang mempu memberi sukacita sejati kepada kita seperti yang Tuhan Yesus berikan. Ia rela mengorbankan diri agar sukacita itu tetap menjadi milik kita sampai pada kehidupan yang kekal.

Dalam keseluruhan perayaan Jumat Agung di Gereja Ganjuran tanggal 22 April 2011 ada dua kelompok instrumen yang digunakan yaitu gamelan dan trebangan. Gamelan merupakan instrumen yang sudah lama digunakan dalam perayaan liturgi di Gerja Ganjuran dan mendukung umat dalam menghayati makna perayaan liturgi terutama Jumat Agung karena melodinya yang tenang dan mengalun. Hal ini nampak dari ekspresi umat yang khusuk berdoa ketika mendengarkan alunan musik tersebut. Lagu yang 
diiringi gamelan dalam perayaan ini terdiri dari 10 lagu yaitu Sungkawa (diiringi beberapa instrumen gamelan), Ayak-ayak Tlutur (perangkat lengkap gamelan), Gusti Midhangetna (perangkat lengkap gamelan), Ngabekti Salib (beberapa instrumen), Ing Ratri (perangkat lengkap gamelan), Sri Yesus $D i$ (perangkat lengkap gamelan), Atur Roncen (perangkat lengkap gamelan), Rama Kawula (beberapa instrumen), Puji Luhung (perangkat lengkap gamelan) dan Sri Yesus Manis Ing Manah (perangkat lengkap gamelan).

Trebangan merupakan alat musik yang baru pertama kalinya digunakan di Gereja Ganjuran dalam perayaan Jumat Agung. Sebelumnya alat musik ini sering digunakan untuk mengiringi perayaan-perayaan liturgi lainnya. Yakobus Pasrah Harjanto selaku staf pengurus alat musik ini menjelaskan bahwa mereka memiliki paguyuban khusus yang dinamakan Palawija. Nama ini merupakan singkatan dari Paguyuban Langen Wirama Jawa. Palawija sudah berdiri sejak tahun 1998 dengan tujuan untuk memuji Tuhan lewat alat-alat musik trebangan. Menurut Pasrah, mereka memuji Tuhan lewat alat musik trebangan tidak harus dalam perayaan liturgi tetapi dalam kegiatan-kegiatan kesenian lainnya karena itu mereka aktif bermain dalam festival-festival kesenian. Mereka bersyukur karena alat musik ini dapat digunakan untuk mengiringi perayaan liturgi walaupun masih ada umat tertentu yang belum bisa menerimanya.

Khusus dalam perayaan Jumat Agung, terdapat empat lagu yang diiringi musik trebangan palawija yaitu Gya Sumewa, Salib Suci, Megatruh dan Linuhurna Gusti. Walaupun hanya untuk mengiringi dua lagu namun alat musik ini menjadi sorotan umat karena iramanya cukup kontras dengan irama musik gamelan. Umat pada dasarnya belum setuju dengan penggunaan alat musik ini dalam perayaan Jumat Agung karena iramanya lebih merupakan ekspresi perasaan sukacita walaupun lirik lagu yang diiringinya sesuai dengan tema perayaan.

\section{Penutup}

Musik liturgi inkulturatif memiliki peran penting dalam menghantar umat untuk menghayati nilai-nilai liturgi secara baik. Perayaan Jumat Agung merupakan sebuah perayaan liturgi resmi Gereja Katolik yang bisa diselenggarakan secara inkulturatif, baik doa-doa, bacaan maupun musik liturginya. Dalam hal ini kesesuaian antara musik liturgi inkulturatif itu dengan ketentuanketentuan mengenai musik liturgi yang berlaku dalam Gereja Katolik universal merupakan hal urgen yang mesti diperhatikan.

Setelah melewati proses penelitian dan analisis tentang musik liturgi inklulturatif dalam perayaan Jumat Agung di Gereja Ganjuran, dapat disimpulkan bahwa musik liturgi inkulturatif dalam perayaan Jumat Agung di Gereja Ganjuran tanggal 22 April 2011 secara keseluruhan ada yang sesuai dan ada pula yang tidak sesuai dengan ketentuan-ketentuan yang berlaku tentang musik liturgi. Lagu-lagu yang sesuai dengan ketentuanketentuan tentang musik liturgi adalah Sungkawa, Ayak Ayak Tlutur, Gya Sumewa, Gusti Midhangetna, Ngabekti Salib, Salib Suci, Megatruh, Ing Ratri Njeng Gusti, Atur Roncen, Sri Yesus Di, Rama Kawula dan Sri Yesus Manis Ing Manah. Beberapa pendasaran yang memperkuat kesimpulan ini yakni lagu-lagu tersebut sesuai dengan tema perayaan Jumat Agung yakni peringatan sengsara dan wafat Tuhan Yesus Kristus. Selain itu, berdasarkan pengamatan penulis dan pendapat beberapa umat yang sempat diwawancarai, umat ikut berpartisipasi dalam menyanyikan lagu-lagu tersebut dan didukung dalam menghayati makna perayaan Jumat Agung.

Lagu-lagu yang tidak sesuai dengan ketentuanketentuan tentang musik liturgi adalah Linuhurna Gusti dan Puji Luhung. Alasannya karena lirik lagu-lagu tersebut bertentangan dengan tema perayaan Jumat Agung. Linuhurna Gusti berisikan lagu kemuliaan kepada Allah Tritunggal Maha Kudus yang tidak diijinkan untuk dinyanyikan selama masa pra paskah sampai perayaan Jumat Agung. Puji Luhung berisikan nyanyian pujian Maria (magnificat) dan tidak cocok dinyanyikan pada perayaan Jumat Agung yang merupakan perayaan peringatan sengsara dan wafat Tuhan Yesus Kristus puteranya. Memang figur Maria pantas ditampilkan dalam perayaan ini namun jenis lagu yang dipilih tidak sesuai, akan sesuai apabila diangkat lagu Maria yang mengungkapkan kesedihan seperti Stabat Mater Dolorosa.

Mengenai musik instrumen yang mengiringi lagu-lagu di atas, penulis memiliki dua penilaian berbeda. Pertama, musik gamelan cocok untuk mengiringi lagu-lagu pada perayaan Jumat Agung. 
Warna suara instrumennya mendukung suasana duka yang sedang berlangsung berkenaan dengan misteri penderitaan dan wafat Tuhan Yesus. Selain itu, beberapa wakil dari kalangan umat juga mengungkapkan bahwa alunan nada-nada dari instrumen tersebut sungguh menghantar mereka ke dalam suasana doa yang khusuk dan hikmat. Kedua, musik trebangan belum cocok mengiringi lagu-lagu dalam perayaan Jumat Agung. Umat yang dimintai pendapat pada umumnya tidak setuju dengan penggunaan musik instrumen ini dalam perayaan Jumat Agung karena irama musik tersebut tidak selaras dengan suasana sedih dalam perayaan Jumat Agung. Irama musik ini memiliki loncatan-loncatan ritmis yang hidup dan tidak nampak sedih.

\section{Kepustakaan}

Bakker, J.W.M. 1984. Filsafat Kebudayaan. Yogyakarta: Kanisius.

Fellerer, Karl Gustav. 1961. The History of Catholic Church Music. Baltimore: Helicon Press.

Hadi, Y. Sumandyo. 2006. Seni Dalam Ritual Agama. Yogyakarta: Penerbit Buku Pustaka.

Hardawiryana, R. (penterj.). 1990. Konstitusi Tentang Liturgi Suci. Jakarta: Departemen Dokumentasi dan Penerangan KWI.

Komisi Liturgi KWI. 1993. Ibadat Harian. Ende: Nusa Indah.

Machlis, Joseph. 1977. The Enjoyment of Music. New York: w.w. Norton \& Company.

Paul Widyawan. 2007. "Memutar Kembali Roda Inkulturasi” dalam Warta Musik Edisi 06.
Prier, Karl-Edmund. 1999. Inkulturasi Musik Liturgi. Yogyakarta: Pusat Musik Liturgi. 2009. Kamus Musik. Yogyakarta: Pusat Musik Liturgi. . 2010. Kedudukan Nyanyian

Dalam Liturgi.Yogyakarta: Pusat Musik Liturgi.

2007. Perjalanan Musik Gereja Katolik Indonesia Tahun 1957-2007. Yogyakarta: Pusat Musik Liturgi.

Susantina, Sukatmi. 2001. Inkulturasi Gamelan Jawa. Yogyakarta: Philosophy Press.

\section{Informan}

Aji, Agustinus Windu (40 tahun), seniman. Ganjuran.

Pasrah, Yakobus Harjanto (61 tahun), pengurus paguyuban musik palawija. Ganjuran.

Priyono, Antonius Jarot Kusno (51 tahun), Pastor Paroki Hati Kudus Tuhan Yesus Ganjuran. Bantul, Yogyakarta.

Santoso, Budi (58 tahun), dosen musik Institut Seni Indonesia (ISI) Yogyakarta sekaligus koordinator seksi musik liturgi paroki Hati Kudus Tuhan Yesus Ganjuran pada perayaan Jumat Agung tanggal 22 April 2011. Ganjuran.

Sukisno (65 tahun), umat paroki Hati Kudus Tuhan Yesus Ganjuran sekaligus penabuh gamelan dalam perayaan Jumat Agung tanggal 22 April 2011. Ganjuran.

Utomo, Gregorius, Pr (82 tahun), pastor pembantu paroki Hati Kudus Tuhan Yesus Ganjuran. Bantul, Yogyakarta. 